\title{
Non-Invasive Assessment of the Liver - Serum Markers and Imaging Techniques
}

\author{
Anna Mania, Paweł Kemnitz, Katarzyna Mazur-Melewska, \\ Magdalena Figlerowicz and Wojciech Służewski \\ Department of Infectious Diseases and Child Neurology, \\ University of Medical Sciences, Poznan, \\ Poland
}

\section{Introduction}

Management and prognosis of the liver diseases highly depends on the advancement of the liver lesions. It is particularly important to distinguish patients at greatest risk of developing liver cirrhosis, liver failure and hepatocellular carcinoma. Liver biopsy remains the gold standard for evaluating the liver tissue. It allows not only for establishing the grade of inflammatory activity and the stage of fibrosis, but also for more accurate differential diagnosis and detection of coexisting liver diseases. Needle biopsy removes, however, only about $1 / 50,000$ of the liver tissue and carries the risk of sampling error. Furthermore, the specimen should be sufficient in length $(20-25 \mathrm{~mm})$, width, fragmentation and number of complete portal tracts (at least 11) [Cholongitas et al., 2006]. Moreover, liver assessment is affected by significant interpretative error and interobserver variability of histological interpretation. Besides, many patients are reluctant to experience repeated biopsies, which limits the ability to monitor disease progression and the effects of treatments.

Search for new non-invasive approaches have been initiated as a result of the limitations of the liver biopsy. Non-invasive tests for the assessment of the severity of chronic liver diseases seem to be an attractive option designed to replace liver biopsy in the near future.

Ideal non-invasive marker of particular liver lesion should be reliable, liver specific, inexpensive and easy to perform. In addition, it should allow not only to diagnose particular liver problem but also to monitor its progression. Recently extensive research is performed to evaluate non-invasive techniques for the detection of liver fibrosis, necroinflammatory activity and steatosis in various liver diseases. This chapter revises currently used noninvasive techniques of liver assessment.

\section{Serum biochemical markers}

\subsection{Serum markers of fibrosis in hepatitis}

The progression of liver fibrosis is a complex wound-healing process, that involves various types of cells and their mediators that eventually leads to the deposition and accumulation of various extracellular matrix (ECM) components. 
Serum biochemical tests including direct and indirect markers of fibrosis have been most widely investigated. Certain markers, especially cytokines, growth factors, metaloproteinases and their inhibitors may reflect balance or imbalance between fibrogenesis and fibrinolysis, revealing information about the progression of the disease.

\subsection{Direct markers}

Direct markers include profibrotic cytokines as transforming growth factor beta-1 (TGF beta-1), ECM components - glycoproteins as hyaluronan (HA), laminin, metaloproteinases their tissue inhibitors and others. Some of them demonstrated associations with liver fibrosis.

Fibryl-forming collagens accumulate in the process of liver fibrosis being important components of extracellular matrix. The most extensively studied collagen is PIIINP, an aminotreminal peptide of procollagen III, that is cleaved from procolagen III during its secretion by fibroblasts. Therefore, it is mainly considered to be a marker of fibrogenensis, rather than fibrosis. PIIINP was found proportional to the liver fibrosis in several studies. However, this parameter should be validated in further studies, as it is too early to recommend its use as a single marker [Leroy et al., 2004].

Transforming growth factor beta 1 (TGF-beta 1) is a cytokine that activates fibrogenesis and inhibits fibrinolysis. This protein stimulates mesenchymal cells and increases production of ECM components. TGF-beta 1 was found to be related to the liver fibrosis in patients with CHC and CHB [Marek et al., 2003].

Laminin is a glycoprotein of ECM consisting of 3 different polipeptide chains $\alpha, \beta$, and $\gamma$. Laminins take part in the cellular adhesion, stimulate cellular growth and act as cellular mediators. This protein is also considered to be a marker of the liver fibrosis. In various studies it was found to be related to the degree of the liver fibrosis in patients with $\mathrm{CHC}$ [Walsh et al., 2000].

Hyaluronic acid (HA) a glycosaminoglycan produced by fibroblasts that seems to be a major component of extracellular matrix. Liver sinusoidal cells are responsible for degradation of its particles. Therefore elevated HA serum levels may reflect endothelial dysfunction associated with the progression of fibrosis. Several studies proved correlation between HA serum levels and hepatic fibrosis, it has, however limitations in distinguishing exact stages [Patel et al., 2003]. HA was validated in HCV, HBV and $\mathrm{HCV} / \mathrm{HIV}$ coinfected patients. Serum concentrations of HA were found to be related to the level of fibrosis. However, in lower fibrosis stages serum HA levels may overlap, therefore the parameter is more reliable in advanced stages of fibrosis [Resino et al., 2010]. $\mathrm{HA}<60 \mathrm{ug} / 1$ exclude fibrosis and extensive fibrosis, whereas values $>110 \mathrm{ug} / 1$ predicted cirrhosis [McHutchinson et al., 2002].

Metaloproteinases (MMPs) and their tissue inhibitors (TIMPs) are proteins involved in the regulation of fibrogenesis and fibrinolysis. MMPs are secreted by fibroblasts and Kupfer cells in inactive form that requires further cleavage for functional capability. They are involved in degradation of extracellular matrix components and are regulated by tissue inhibitors (TIMPs). MMP-2 is an enzyme up-regulated by collagen type II, that was found to be positively related to the liver fibrosis. Similar correlations were found for TIMP-1 and TIMP-2. Moreover, TIMP-1 was found to be very sensitive and displayed good specificity for the detection of liver cirrhosis [Boeker et al., 2002]. In combination with HA and PIIINP, TIMP-1 showed good accuracy for the diagnosis of extensive fibrosis and cirrhosis [Leroy et al., 2004]. 
Although direct markers are less expensive than the liver biopsy, they are still costly and are not available in most clinical settings. Therefore, none of those biomarkers is until now in frequent use except for research studies.

\subsubsection{Indirect markers}

Indirect markers associated with fibrosis, such as routine biochemistry, platelets, and alpha2-macroglobulin, are widely available in daily clinical practice. Biochemical tests mainly include aspartate (AST) and alanine aminotransferase (ALT) activity and prothrombine time. They are either tested alone or in combination, which enhances their value. Prothrombine time, a well-known marker of hepatic dysfunction, was negatively correlated to fibrosis even in its earlier stages [Croquet et al. 2002]. Thrombin is believed to be trapped by the hepatic sinusoidal capillary network and bind to the receptors on the surface of activated hepatic stellate cells.

AST levels usually increase in patients with liver fibrosis as a result of reduced clearance by sinusoidal capillary network. AST/ALT ratio was found related to the presence of liver cirrhosis with high predictive values for ratio exceeding 1 . Nevertheless, not all studies confirm such results. Diagnostic value of AST/ALT ratio was improved by its combination with platelet count below $150 \mathrm{G} / 1$. Number of platelets declines with the progression of liver fibrosis as a consequence of sequestration in the spleen but also reduced thrombopoetin production.

Indirect markers are cost-free, thus they have not been tested in less advanced cases of liver fibrosis. Recent studies combine these markers to produce valuable scores. Several indirect markers and have been incorporated into composite panels that have been developed to evaluate the presence hepatic necroinflammation and fibrosis.

FibroTest- Acti-Test consisting of the panel of selected biochemical markers was designed to evaluate liver fibrosis and necroinflammatory activity in chronic hepatitis $\mathrm{C}$ (CHC) [Poynard et al., 2002; Myers et al., 2003]. The test consist of six biochemical markers: alfa2macroglobulin (A2-M), haptoglobin (HPT), gamma glutamyltranspeptidase (GTP), total bilirubin, apolipoprotein A1 (ALP-A1) and ALT that are adjusted to the patient age and gender in a patented algorithm. No single blood test possesses sufficient negative or positive predictive value to substitute for liver biopsy, especially for the diagnosis of moderate fibrosis (F2). Each of the components adds complementary value to, the estimation of fibrosis and necroinflammatory activity. A2-M is a protein synthesized by hepatocytes, stellate cells and granulomas, which serum concentration increases during stellate cell activation in the course of fibrogenesis. As proteinases inhibitor it can increase fibrosis by inhibiting the breakdown of extracellular matrix proteins. HPT is a protein synthesized by the liver which serum level decreases with fibrosis. This decline does not depend on hemolysis or hepatic insufficiency. In the circumstances of the liver fibrosis HPT synthesis is decreased by hepatic growth factor. ALP-A1 is a protein synthesized by hepatocytes, responsible for the transport of the cholesterol. In liver fibrosis, its release is hampered by the ECM collagen fibers, moreover its transcription is equally reduced. Serum apolipoprotein A1 levels declines in the presence of fibrosis. Bilirubin is a pigment resulting from the degradation of hemoglobin, which in normal conditions is taken up from the blood, conjugated and excreted in bile. Bilirubin increases in liver fibrosis. Hepatitis $C$ virus infection modifies the transporters of bilirubin that could explain the increase observed in the early stages of fibrosis. GTP is an enzyme synthesized by hepatocytes, which increases with fibrosis on unknown mechanisms, that are independent of the growth in 
aminotransferases and bilirubin. It is believed that epidermal growth factor stimulates the synthesis of GTP during of fibrogenesis. ALT is an enzyme synthesized by hepatocytes, which increases in serum when necrosis and hepatic tissue inflammation occur. FibrotesActitest was proven to have high predictive value in $\mathrm{CHC}$ patients before and after antiviral treatment [Poynard et al., 2001], in patients with persisting normal ALT activity [Colletta et al., 2005], coinfected with HIV [Myers et al., 2003]. The test was also found useful in chronic hepatitis B (CHB) [Myers et al., 2003], alcoholic liver disease [Naveau et al., 2005], nonalcoholic fatty liver disease (NAFLD) [Ratziu et al., 2006] and hemochromatosis [Adhoute $X$ et al., 2006]. The test was also confirmed to other single direct and indirect markers as well as the test panels. Its main disadvantage are false positive results induced by ribavirin treatment on HPT levels. Numerous publications were released concerning this method of assessment in various liver diseases. It enables direct extrapolation from the results of the test to the stages of fibrosis in different scoring systems (Table 1). The test is available on commercial bases. Thus, the chief researcher involved in validation of the test has financial interests in its manufacturing company.

\begin{tabular}{|c|c|c|c|}
\hline Fibrotest & $\begin{array}{c}\text { METAVIR fibrosis stage } \\
\text { estimate }\end{array}$ & $\begin{array}{c}\text { Knodell fibrosis stage } \\
\text { estimate }\end{array}$ & $\begin{array}{c}\text { Ishak fibrosis stage } \\
\text { estimate }\end{array}$ \\
\hline $0.75-1.00$ & F4 & F4 & F6 \\
\hline $0.73-0.74$ & F3-F4 & F3-F4 \\
\hline $0.59-0.72$ & F3 & F3 & F4 \\
\hline $0.49-0.58$ & F2 & F1-F3 & F3 \\
\hline $0.32-0.48$ & F1-F2 & F1-F3 & F2-F3 \\
\hline $0.28-0.31$ & F1 & F1 & F2 \\
\hline $0.22-0.27$ & F0-F1 & F0-F1 & F1 \\
\hline $0.00-0.21$ & F0 & F0 & F0 \\
\hline
\end{tabular}

Table 1. Conversion between the results of FibroTest and fibrosis stages in METAVIR, Knodell and Ishak scoring systems. Fibrosis scoring systems.

Beside Fibrotest-Actitest, more panels of direct and indirect markers were developed.

FibroSpect evaluates liver fibrosis by analyzing the following parameters: hyaluronic acid, tissue-inhibited matrix metalloproteinase inhibitor-1 and a-2 macroglobulin [Patel et al., 2004]. The score is licensed and commercially available in the USA. Validated in several studies, the test was proven to be effective for excluding significant fibrosis and cirrhosis. Positive predictive values for detecting fibrosis were found much lower than negative values for excluding significant fibrosis or cirrhosis [Zaman et al., 2007].

Fibrosure combines quantitative results of the following parameters: A2-M, HPT, GTP, total bilirubin, ALP-A1 and ALT with a patient's age and gender in a patented artificial 
intelligence algorithm to create a measure of fibrosis and necroinflammatory activity in the liver. The test is an American form of Fibrotest and provides continuous numerical assessment of liver fibrosis and necroinfalmmatory activity corresponding to METAVIR scoring system. Values $<0.48$ exclude significant fibrosis while a score $>0.78$ is highly predictive for the liver cirrhosis. Values $<0.36$ indicate minimal activity, while scores $>0.62 \mathrm{a}$ specific for severe necroinflammatory activity [Poynard et al., 2004].

Hepascore includes bilirubin, GTP, A-2M, HA, age and gender [Adams et al. 2005]. A score $>0.5$ indicated significant fibrosis with $92 \%$ of specificity and $67 \%$ of sensitivity. While scores $<0.5$ had $74 \%$ specificity and $88 \%$ sensitivity to exclude advanced fibrosis. A cutoff of 0.84 had a $71 \%$ specificity and $89 \%$ of sensitivity for the prediction of liver cirrhosis. However, there was a significant overlap between patients with mild and moderate fibrosis.

Fibroindex was a proposed score that includes: platelets, AST levels and gammaglobulin according to the formula: Fibroindex $=1.738-0.064 \times$ platelets $\left(10^{4} / \mathrm{mm}^{3}\right)+0.005 \times$ AST $(\mathrm{IU} / \mathrm{l})+0.463 \times$ gammaglobulin $(\mathrm{g} / \mathrm{dl})$. Two threshold were proposed for the diagnosis of significant fibrosis. A score $>1.25$ confirmed fibrosis with $94 \%$ of specificity and $>2.25$ with $97 \%$ of specificity [Koda et al. 2007].

Forns score combines: age, GTP, cholesterol level, platelet count according to the formula: Forns score=7.811-3.131 $\times \ln$ platelets $(\mathrm{g} / \mathrm{l})+0.781 \times \ln \mathrm{GTP}(\mathrm{IU} / \mathrm{l})+3.647 \times \ln$ age(years) -0.014 $x$ cholesterol [Forns et al. 2002]. A score $<4.2$ excluded and a score $>6.9$ confirmed significant fibrosis. The main limitation of the scale is that the result is indefinite in many patients and no thresholds were created for the diagnosis of extensive fibrosis or cirrhosis. Thus, lipid abnormalities observed in hepatitis patients raise concerns related to the utility of the scale and requires further validation for the use in routine clinical practice.

APRI score is AST/platelets ratio calculated as (AST/upper normal limit X 100/platelet count) [Wai et al 2003] originally proposed for hepatitis $C$ patients. In original study a score $<0.5$ ruled out significant fibrosis, a score $<1.0$ excluded cirrhosis and a score $>2.0$ suggested cirrhosis with good predictive value. Nevertheless, subsequent studies in hepatitis $C$ and HIV coinfected patients had much poorer outcome. This score was found to be useful to exclude significant fibrosis and particularly cirrhosis with around $90 \%$ certainty also in HCV infected hemodialysis patients [Schiavon et al., 2007]. The results were, however much worse in alcoholic patients as alcohol may have direct effects on AST activity and platelet count. Therefore this limitation should be taken into account in daily clinical practice [Trabut et al., 2009]. APRI may be used as an easy first-line investigation, however, not as the only tool as it has moderate diagnostic utility for the prediction of fibrosis in HCVinfected patients. Its major role appears to be the exclusion of significant fibrosis and cirrhosis, which can be achieved with acceptable accuracy in at least one third and three quarters of patients, respectively [Shaheen and Myers, 2007].

FIB-4 uses the following formula: (age X AST/platelets X ALT) ${ }^{1 / 2}$ [Vallet-Pichard et al., 2007]. Values $<1.45$ ruled out extensive fibrosis and $>3.25$ confirmed the diagnosis with around $90 \%$ of accuracy in comparison to the histological results in the Ishak scoring system. Significant proportion of patients fell into indeterminate range of results.

Although these test give promising results in detecting advanced fibrosis their ability to replace liver biopsy is still not probable as some of them have not been sufficiently validated [Bourliere 2006]. Some of the scores like APRI may be influenced by other factors like for example alcohol abuse that may influence on the level of indirect markers in the scale. Diagnostic panels were presented in Table 2. 


\begin{tabular}{|c|c|c|c|}
\hline Score & Parameters involved & Formula & Reference \\
\hline $\begin{array}{l}\text { Fibrotest- } \\
\text { Actitest }\end{array}$ & $\begin{array}{c}\text { alfa2-macroglobulin } \\
\text { haptoglobin } \\
\text { GTP } \\
\text { total bilirubin } \\
\text { apolipoprotein A1 } \\
\text { ALT } \\
\text { Age } \\
\text { gender }\end{array}$ & $\begin{array}{l}\text { Patented and commercially } \\
\text { used }\end{array}$ & $\begin{array}{l}\text { Poynard } \\
\text { et al. } 2002\end{array}$ \\
\hline FibroSpect & $\begin{array}{l}\text { hyaluronic acid } \\
\text { tissue-inhibited matrix } \\
\text { metalloproteinase } \\
\text { inhibitor-1 } \\
\text { a-2 macroglobulin }\end{array}$ & $\begin{array}{l}\text { Licensed and commercially } \\
\text { used }\end{array}$ & $\begin{array}{l}\text { Patel et } \\
\text { al. } 2004\end{array}$ \\
\hline FibroSure & $\begin{array}{l}\text { alfa2-macroglobulin } \\
\text { haptoglobin } \\
\text { GTP } \\
\text { total bilirubin } \\
\text { apolipoprotein A1 } \\
\text { ALT }\end{array}$ & $\begin{array}{l}\text { The USA patented form of } \\
\text { Fibrotest-Actitest }\end{array}$ & $\begin{array}{l}\text { Poynard } \\
\text { et al } 2004\end{array}$ \\
\hline Hepascore & $\begin{array}{c}\text { Bilirubin } \\
\text { GTP } \\
\text { a-2 macroglobulin } \\
\text { hyaluronic acid } \\
\text { age } \\
\text { gender }\end{array}$ & $\begin{array}{c}\text { Hepascore }=\mathrm{y} / 1+\mathrm{y} ; \\
\mathrm{y}=\mathrm{exp}[4.185818-(0.0249 \mathrm{x} \\
\text { age }+(0.7464 \mathrm{x} \text { sex }+1.0039 \mathrm{x} \\
\text { a2-macroglobulin }+(0.0302 \mathrm{x} \\
\text { hyaluronic acid })+(0.0691 \mathrm{x} \\
\text { bilirubin })-(0.0012 \times \text { GGT })]\end{array}$ & $\begin{array}{l}\text { Adams et } \\
\text { al. } 2005\end{array}$ \\
\hline Fibroindex & $\begin{array}{c}\text { PLT } \\
\text { AST } \\
\text { gammaglobulin }\end{array}$ & $\begin{array}{c}\text { Fibroindex }=1.738-0.064 x \\
\text { PLT }\left(10^{4} / \mathrm{mm}^{3}\right)+0.005 \times \text { AST } \\
(\mathrm{IU} / \mathrm{l})+0.463 \times \\
\text { gammaglobulin }(\mathrm{g} / \mathrm{dl})\end{array}$ & $\begin{array}{l}\text { Koda et } \\
\text { al. } 2007\end{array}$ \\
\hline APRI & $\begin{array}{l}\text { AST } \\
\text { PLT }\end{array}$ & $\begin{array}{c}\text { APRI }=\text { AST level }(/ \text { ULN }) \\
\text { x100 } \\
\text { PLT }\left(10^{9} / \mathrm{L}\right)\end{array}$ & $\begin{array}{l}\text { Wai et al. } \\
2003\end{array}$ \\
\hline FIB-4 & $\begin{array}{l}\text { Age } \\
\text { AST } \\
\text { ALT } \\
\text { PLT }\end{array}$ & 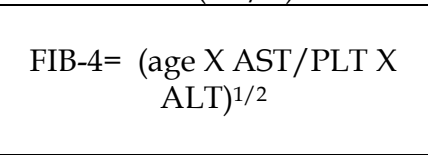 & $\begin{array}{l}\text { Vallet- } \\
\text { Pichard et } \\
\text { al. } 2007\end{array}$ \\
\hline
\end{tabular}

Abbreviations: AST - aspartate aminotransferase, ALT - alanine aminotransferase, GTP- gamma glutamyltranspeptidase, UNL - upper normal limit, PLT - platelet count

Table 2. Serum diagnostic panels of direct and indirect markers.

\subsection{Serum markers of steatosis}

Several studies proposed various tests to distinguish between simple steatosis and NASH in patients with NAFLD. The most important parameters are acute phase proteins as they enable to establish NASH. Several markers of inflammation were extensively studied in relation to fatty liver disease. C-reactive protein (CRP) is an acute phase parameter that is produced in the liver and increases in various inflammatory conditions. The evaluation of serum CRP levels was found to be associated with NASH and helps to differentiate this 
condition from simple steatosis. Furthermore, high levels of high-sensitivity CRP were found to be associated with extensive liver fibrosis in NASH [Yoneda et al. ,2007].

Nevertheless, study conducted in children with liver steatosis revealed that fatty liver itself may not be a cofactor in stimulating inflammatory markers in obese patients. Obese children with NAFLD may have simple steatosis and their increased inflammatory markers are therefore compatible with those expected in obesity [Neuman et al. ,2010].

Another acute phase protein used to distinguish NASH from non-NASH patients is plasma pentraxin-3 (PTX 3) a novel marker that seems to be promising in assessing the severity of fibrosis. Plasma PTX-3 levels were, however, found increased not only in NASH, but also in other cardiovascular and inflammatory conditions and vasculites [Yoneda et al., 2008].

Interleukin-6 seems to be another marker playing an important role in fatty liver disease. This biomarker is a cytokine synthesized in hepatocytes, endothelial cells, adipocytes and cells of the immune system, that rises in NAFLD and indicates inflammatory activity and liver fibrosis [Wieckowska et al. , 2008].

Tumor necrosis factor-alpha (TNF-alpha) is another proinflammatory cytokine which role in NASH was clearly established. As levels of TNF-alpha are increased in NASH, anti-TNFalpha therapy was found effective in the improvement of liver histology and normalization of aminotransferase levels.

Cytokeraitn-18 is a marker of hepatic apoptosis and is utility in the detection of NASH is based on the observation that apoptosis is prominent in NASH and absent in simple steatosis. Its use is, however, so far limited to research areas [Wieckowska et al. , 2008].

As oxidative stress has been found to play an important role in NASH pathogenesis several parameters were evaluated in various studies: vitamin E levels, glutathione peroxidase activity and superoxide dismutase activity [Hardwick et al.,2010]. None of these markers reflect liver histology in NASH, therefore its clinical value is still questionable and were not entirely defined yet. The assessment of the liver fibrosis is an important component in the evaluation of NASH as end stage liver disease is constantly present in this state. Several matrix components have been studied in various trials: HA, TGF beta-1, TIMP and other markers. Nevertheless so far none of them entered clinical use.

To avoid liver biopsy several noninvasive panels of serological markers have been developed to assess the presence of hepatic necroinflammation and steatosis. SteatoTest is a quantitative test designed to estimate liver steatosis especially in patients with metabolic syndrome [62]. NASH test is a variation of SteatoTest and ActiTest for the differentiation of simple steatosis from NASH and should be performed only if SteatoTest is positive. The scores combine various parameters. The NASH test combines total bilirubin, GGT, a2macroglobulin, apolipoprotein A1, haptoglobin and ALT, and is adjusted for age and gender plus weight, height, AST, serum glucose, triglycerides, cholesterol and SteatoTest.

NASH FibroSURE is the USA patented algorithm combining quantitative results of 10 biochemical parameters, including A2M, HPT, ALP-A1, bilirubin, GTP, ALT, AST, total cholesterol, triglycerides, and fasting glucose, in relation to the age, gender, height, and weight. The registered algorithm provides quantitative alternate markers for liver fibrosis, hepatic steatosis, and NASH. Markers of fibrosis are corresponding to METAVIR scoring system. Marker of hepatic steatosis varies from S0 to S3 and is corresponding to $0 \%$ to $>66 \%$. In a study conducted on patients with significant $(>5 \%)$ steatosis score a value $>0.5$ confirmed steatosis with high sensitivity and specificity [Poynard et al., 2005]. The test also provides a diagnostic assessment of the presence of NASH using three broad categories N0$\mathrm{N} 2$ corresponding to "Not NASH," "Borderline NASH," and "NASH" per the Kleiner classification [Kleiner et al.;2005]. 
Other tests combine both direct and indirect markers or other clinical parameters: age, gender, BMI, AST, AST/ALT ratio, hyaluronan [Palekar et al., 2006] or adiponectin and collagen type IV [Shimada et al., 2007].

Various test panel were compared with one another. The results are, however, ambiguous and vary from study to study. Although patented commercial tests seem to present a higher diagnostic value, simply non-patented panels are much easier available.

\section{Transient elastography}

Non-invasive assessment of the liver fibrosis is also possible by transient elastography. The technique is performed by device called Fibroscan that enables the assessment of the liver stiffness. The device holds an ultrasound probe in a vibrating piston that induces elastic vibrations propagating through the liver. The reflected waves captivated by a transducer enable to measure the liver elasticity that is inversely related to the speed of the waves [Sandrin 2003]. After several measurements, calculated mean value enables the exact assessment of liver fibrosis. This method was proven precise enough when compared to the liver biopsy and evaluates a portion of the liver 500 times bigger than conventional method [Castera 2005]. Transient elastography is described in detailed in another chapter of this book. It was also used in combination with serum markers of fibrosis. The Fibro-Stiffness index is a panel consisting of liver stiffness measured by Fibroscan, platelet count and prothrombin time. The method demonstrated superior diagnostic performance to liver stiffness obtained by elastography alone, the APRI, the Forns score and the FibroIndex for significant and severe fibrosis and liver cirrhosis. The diagnostic value of the Fibro-Stiffness index for liver cirrhosis was increased by combination with serum HA levels [Ichino et al., 2010].

Various test panles were validated either compared to elastography or used simultaneously with this method. The most promising results were obtained were both serum markers and elastography were used together.

\section{Imaging techniques}

Conventional imaging techniques that include ultrasound with Doppler, CT and MRI can be used to evaluate advanced liver cirrhosis. Their ability to detect minor lesions is, however, limited [Hussain 2005].

\subsection{Hepatic ultrasound}

Ultrasonography is simple, inexpensive, easy to reproduce and can be repeatedly used to assess changes over time. It is a first-line imaging technique, a simple non-invasive method, that is widely used in clinical practice to detect fatty infiltration of the liver. It assesses the presence of steatosis detecting a hyperechogenic parenchyma of the liver displayed as "bright liver " or "blurring of the vascular margins". An ultrasound index for quantitative assessment of the liver steatosis is the hepato-renal contrast. Normal liver shows an echostructure similar to renal parenchyma. In liver steatosis the increased echogenity forms hepato-renal contrast. Severity of liver steatosis was assessed according to a discrepancy in ultrasonographic liver-kidney densities. The hepato-renal index was supposed to quantify the severity of liver steatosis to a lower limit of 5\% [Webb et al. ,2007].

Spleen longitudinal parameter is another simple, noninvasive and easy to perform parameter, that could differentiate between NAFLD and NASH better than serum markers with values exceeding $11.6 \mathrm{~cm}$ for predicting NASH. 
When the degree of steatosis is less than $30 \%$, sensitivity of this technique is low. Moreover, it is impossible to detect inflammatory changes of the hepatic parenchyma and to differentiate between simple steatosis and staeatohepatitis. Therefore, it is very difficult to distinguish between the liver steatosis and liver fibrosis as both changes look similar on ultrasound.

The biggest limitation of this technique is morbid obesity as ultrasonographic examination is difficult to perform in such patients. Ultrasonography is, however, insufficient for detecting early and intermediate stages of fibrosis.

\subsubsection{Doppler ultrasound}

Doppler ultrasound is another helpful tool in the diagnosis of steatosis. Hepatic parenchyma perfusion abnormalities were observed in NASH. Altered hepatic hemodynamics can be described by various parameters including, among others, hepatic vein Doppler pattern and Doppler perfusion index (DPI), which is a ratio between hepatic arterial blood flow and total liver blood flow. DPI allows for the detection of overt liver metastatic disease and helps to differentiate between benign and malignant focal hepatic lesions [Kyriakopoulou et al. ,2008]. DPI was also found predictive of the liver steatosis in patients with NAFLD in the study conducted on a small group of patients, therefore it requires further evaluation [Dugoni et al. 2007]. Conventional Doppler ultrasound examination of hepatic vasculature is, unfortunately not a good tool to evaluate mild and moderate fibrosis. Data reporting the use of hepatic vein blood flow pattern assessment suggests improvements in detecting advanced fibrosis and cirrhosis [Bertzigotti et al., 2010].

\subsubsection{Contrast-enhanced ultrasonography}

This technique allows to overcome limitations of simple ultrasonography. Hepatic vein transit times (HVTT) were evaluated with microbubble contrast agent and were found to predict disease severity in patients with hepatitis $\mathrm{C}$. The uptake of another contrast agent levovist was decreased in NASH due to cell injury, when compared to NAFLD. The study was, however conducted on a small group of patients and should be validated on a larger cohort to establish the role of this technique in clinical practice.

\subsection{Computed tomography}

Computed tomography (CT) provides improved resolution of early liver cirrhosis in the absence of portal hypertension but remains unhelpful in a detection of fibrosis. Even more advanced variations as helical and multidetector row CT reveal early morphological changes with cirrhosis but do not identify fibrosis.

Nevertheless, this conventional technique is a helpful tool in detecting steatosis. Moreover, non-contrast enhanced CT is the best way to identify and characterize hepatic steatosis. Changes in signal sensitivity are related to the liver density, therefore as liver density decreases, the liver steatosis increases. Although abdominal ultrasound is more sensitive in the diagnosis of fatty liver disease, CT scans are more adequate when the fat deposition is focal. They may also be used to evaluate thickened abdominal fatty tissue and to measure the fat in the liver [Davidson et al., 2006]. CT scans may also be used to visualize enlarged spleen and portal hypertension, which may suggest advanced fibrosis. Calculation of the liver-to-spleen attenuation ratio allows grading of steatosis [Park et al., 2006]. As the images appear enhanced, non-contrast CT is chosen for detecting steatosis. Focal fatty lesions may 
be detected by dual-energy CT scans or by contrast enhanced CT. Figure 1 provides picture of multiple fatty lesions in the liver.

However the difficulty to identify intermediate fibrotic stages and the uselessness in the follow-up of the patients due to the exposure to radiation are major limitations of CT.

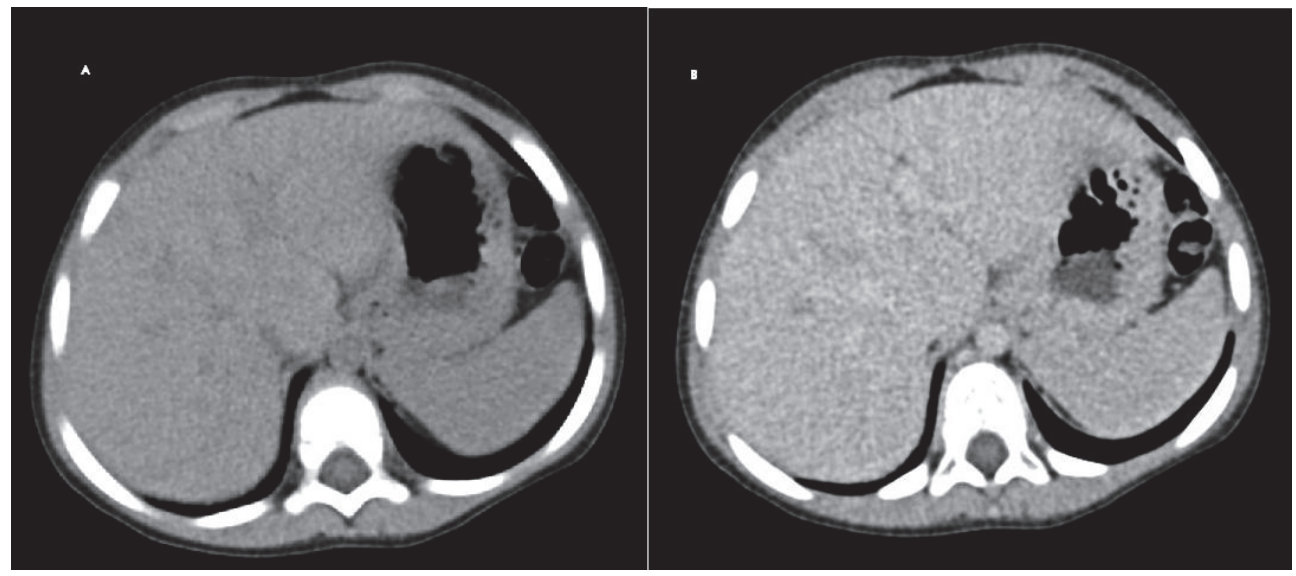

Fig. 1. Computed tomography with multiple focal lesions in the liver (A) of lower density than the liver parenchyma after contrast-enhancement (B) corresponding to hemangiomas.

\subsection{Magnetic resonance imaging}

Magnetic resonance imaging (MRI) reliably identifies cirrhosis but does not show earlier stages of fibrosis. Specific features on MRI including hepatic vein narrowing, caudate to right lobe ratio, and expanded gallbladder fossa, reliably identify cirrhosis but remain absent in earlier stages of fibrosis [Numminen et al., 2005]. This technique provides an accurate and fast evaluation of the liver steatosis even if the degree is low (around 3\%). Good correlation between liver steatosis, MRI and liver biopsy have also been recently demonstrated [Hussain 2005]. Phase-contrast imaging is used for the quantitative assessment of fatty infiltrations in various liver diseases. Lower intensity in T1-weighted images may be used in the detection of focal fat depositions [Szczepaniak et al., 2005].

Significant number of technological advances in developing clinical applications for MRI of the liver have been made over the past decade. Recent improvements focused on using the physiological and biomechanical properties of human liver tissue to improve the detection of focal and diffuse pathological conditions of this organ. New techniques such as magnetic resonance (MR) spectroscopy, diffusion-weight MR, MR elastography are evaluated to examine fibrosis [Talwalkar 2008].

\subsubsection{Contrast-enhanced magnetic resonance imaging}

The development of contrast-enhanced imaging of the liver have been enabled by the introduction of gadolinium chelates to clinical practice. Changes in hepatic parenchyma were described in various studies after contrast-enhanced imaging by MRI [Gandhi et al., 2006]. Early irregular enhancement corresponds to the increased necroinflammatory activity in the liver histology due to higher numbers of macrophages. Whereas, a postponed, heterogeneous enhancement is related to hepatic fibrosis as a result of bright-appearing 
reticulations. This finding may be explained by a reduced distribution of gadolinium in extracellular spaces of the liver [Semelka et al., 2001]. Contrast enhancement depends on the contrast agents. Supermagnetic iron oxide (SPIO) contrast media result in hypointensity within hepatic parenchyma as they accumulate in reticulo-endothelial cells [Yamashita et al., 1996]. The most interesting findings were, however, obtained by sequential administration of gadolinium followed by SPIO contrast agents. Highly accurate SPIO-based images were even improved in accuracy for the detection of liver fibrosis architecture [Aguirre et al., 2006]. Further validation of semi quantitative fibrosis criteria is required to verify the diagnostic performance of this technique.

\subsubsection{Magnetic resonance spectroscopy}

Magnetic resonance spectroscopy (MRS) has been available for the last twenty years allowing evaluation of metabolism of various tissues. The liver is considered to be an ideal organ for MRS due to its anatomical location and increased metabolic demands. MRS is usually used to evaluate signals from hydrogen, which allows for quantitative assessment of lipids and from phosphorus, which reflects cellular turnover and energy state [Solga et al., 2005]. MRS of the liver is performed after a standard MR imaging for localization. Special MR pulse sequences are used to produce spectroscopic data within the suitable anatomical location and volume of interest. Peak area of metabolite signal is directly related to its concentration, which may be expressed in absolute or relative conditions. As the absolute quantification is difficult to obtain in vivo, many studies use metabolite ratios for the evaluation of spectral profiles. Peak areas of the spectrum are compared to standards for correlation with the strength of MR signal. The most widely used standard is adenozyne triphosphate (ATP), taking into account its natural distributions in the tissues. Changes in phospholipids metabolism, reflected in increased phosphomonoesters signal or increased phopsphomonoesters/phosphodiesters ratio in patients with liver cirrhosis, are believed to be associated with regenerating activity - extensive membrane remodeling.

MRS represents useful method for highly accurate noninvasive measurement of liver steatosis [Friedrich-Rust 2010]. This technique measures the fat proton fraction and hepatic trigliceryde level. Concentration exceeding $5 \%$ is a limit of the detection of steatosis. MRS describes metabolic processes of cellular regeneration, therefore it can assess the disease severity in NASH. This technique is probably more accurate for the diagnosis of NAFLD but it requires further validation in humans.

The studies have to be, however, repeated and validated on the larger number of patients with various liver diseases using unified methods.

\subsubsection{Diffusion weight magnetic resonance imaging}

Diffusion-weighted magnetic resonance imaging (DWI) has been widely used for the early detection of cerebral ischemia. This technique measures the freedom of water proton diffusion in tissues and was recently facilitated to be used for abdominal imaging [Naganawa et al., 2005]. As collagen is not reach in unbound water, therefore in the liver fibrosis the amount of water proton diffusion is restricted in affected tissue. DWI produces a signal inversely related to the freedom of water proton diffusion. Tissues with reduced distribution are brighter than normal. The strength of diffusion weighting is described by " $b$ " value of the sequence, which rises with time and amplitude of the gradients responsible for the diffusion. Apparent diffusion coefficient (ADC) of water proton in tissues may be calculated from DWI images. It is determined by the grade of the log intensity set against $b$ 
value [Girometti et al., 2007]. Possibility to display the calculated ADC values as images enable the quantitative analysis by the measurements of the mean values within region of interest. This measurement is usually performed in the right hepatic parenchyma, where major vessels are not present.

Patients with liver cirrhosis were found to have lower ADC compared to healthy individuals. Nevertheless, the results of the studies in patients with various stages of fibrosis are ambiguous with respect to demonstrating a specific relationship between ADC values and fibrosis stage [Koinuma et al., 2005].

Before the DWI becomes more widely used in clinical practice, the studies would have to be conducted on a larger number of patients and properly validated in relation to different hardware and sequencing profiles as currently comparisons are difficult. It was also detected that significant hepatic iron accumulation may considerably reduce signal intensity making DWI impossible in patients with hemochromatosis [Aube et al., 2004]. Fat suppression techniques are necessary in DWI performed in the liver steatosis as otherwise imaging is seriously affected.

\subsubsection{Magnetic resonance elastography}

Many pathological processes as malignancies and liver fibrosis result in increased liver stiffness, which may be detected by physical examination on palpation. Normal liver tissue is similar to fatty tissue on palpation, whereas cirrhotic liver is much harder. Recent reports suggest that the stiffness of hepatic matrix may influence continued differentiation of hepatic stellate cells and the production of fibrosis. Beside ultrasonography-based elastography, a MR-based elastography was described for evaluation of the stiffness of various tissues. The technique uses a phase-contrast method to display the propagation characteristics of acoustic sheer waves generated within the organ of interest [Kruse et al., 2000]. Elastography is usually added to a conventional MR examination of the abdomen with pneumatic or electromechanical driver placed on abdominal wall in the supine patient. The device is used to generate mechanical waves that propagate in the liver at various frequencies [Yin et al., 2007]. A specialized phase contrast MRI sequence, is subsequently used to image the propagating waves in the liver with motion-encoding gradients that are oscillated along with applied movements enabling clear imaging of the waves with very small amplitudes. Provided images represent displacement generated by shear wave propagation in the tissue. They are subsequently processed using a particular inversion algorithm to produce quantitative images describing the tissue stiffness called elastograms. The imaging allows for the measurement of mean elasticity values within the liver, presented in in kilopascals, as in the case of ultrasound-based transient elastography.

Mean liver stiffness in patients with chronic liver diseases was found significantly increased, compared to healthy volunteers in various studies [Klatt et al., 2006]. A quadratic relationship between histological fibrosis stage and elasticity measurements were observed in the studies using ultrasound-based transient elastography. MR elastography was detecting stages 2 to 4 with good sensitivity and specificity. Thus, no relationship between hepatic steatosis and liver stiffness was found. MR elastography was a useful tool to exclude the presence of the liver fibrosis suggesting that this technique could be valuable in finding indications for the liver biopsy [Yin et al., 2007].

Several advantages of this method were observed in relation to its potential use in different populations: potential assessment of entire hepatic parenchyma, operator independence and the ability to obtain a conventional abdominal MRI at the same time. Correspondingly to 
other techniques, the equipment and sequences have to be standardized in order to increase the accuracy of the results and enable comparison of different studies. Further assessment is also necessary to characterize the procedure including its reproducibility among patients with progressive liver disease.

\subsubsection{Multi-echo magnetic resonance}

Multi-echo MRI allows simultaneous T2 and fat content evaluation. This method can be used to define the fat-to-water ratio as well as T2 values [O'Regan et al., 2008].

\subsubsection{Magnetic resonance cholangiopancreatography}

Magnetic resonance cholangiopancreatography $(\mathrm{MRCP})$ is a well-established non-invasive imaging method that creates images of the biliary tree and pancreatic duct without the necessity of intravenous contrast. The images are corresponding to those from endoscopic retrograde cholangiopancreatography (ERCP). The most common indications for this technique include choledocholithiasis, primary sclerosing cholangitis or stricture of bile ducts and others. MRCP also plays an important role in other conditions involving cholangiohepatitis, inborn malformations, tumors and other cysts. The biggest advantage of this technique is the lack of contrast administration, relative operator independence and possibility to evaluate both sides of obstructed ducts with exact stricture size and morphology. Example of MRCP imaging was presented in Figure 2.

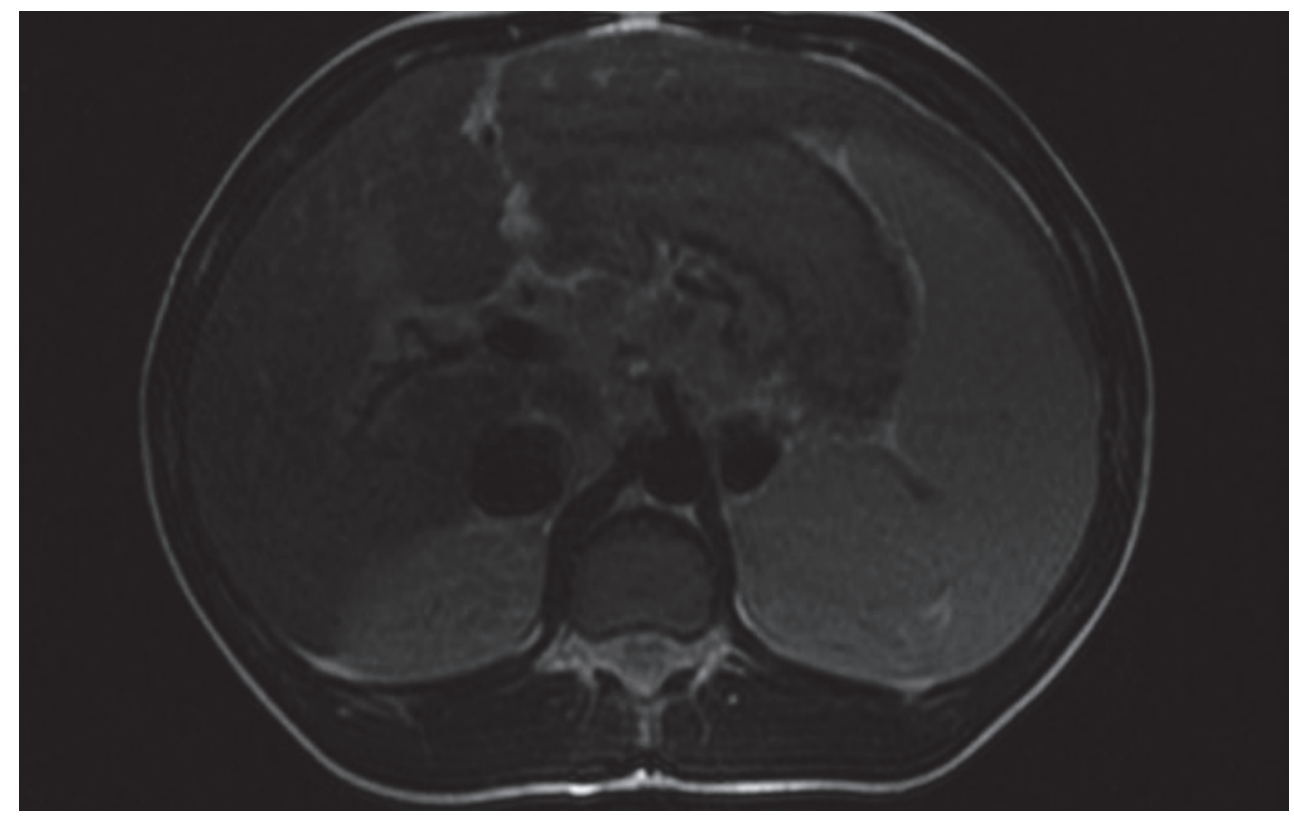

Fig. 2. MRCP image showing the liver of patient with primary sclerosing cholangitis and numerous fibrous septa within the liver with coexisting splenomegaly.

A reliable and valuable noninvasive method to assess hepatic fibrosis would be a very useful clinical tool. Several MR techniques or their combinations are still evaluated to meet 
these requirements and are very promising. Further research is, however necessary to create true functional hepatic imaging.

Clinical utility of imaging techniques is still under evaluation. Advanced MRI techniques are available in tertiary medical centers and it will probably take time before they become widely available. Furthermore, even with this technique some patients may be unable or unwilling to undergo the examination.

\section{Conclusions}

Combination of non-invasive methods like Fibro-test and elastography may substitute the liver biopsy in a near future. They are reliable in patients either with no or progressed fibrosis. Evaluation of intermediate states is, however, difficult. For this reason the liver biopsy remains a most valuable tool in evaluation of the liver and according to current guidelines treatment decisions should be made after liver biopsy. Thus, non-invasive methods may be still an option for patients with contraindications to the liver biopsy or a helpful monitoring tool for those who are reluctant or unable to undergo repeated biopsies.

\section{Acknowledgements}

This paper was supported by a grant from The Ministry of Science and Higher Education No -NN407 012036 to A. Mania

\section{References}

Adams LA, Bulsara M, Rossi E, DeBoer B, Speers D, George J, Kench J, Farrell G, McCaughan GW \& Jeffrey GP. Hepascore: an accurate validated predictor of liver fibrosis in chronic hepatitis C infection. Clin Chem. 2005;51:1867-73

Adhoute X, Foucher J, Castera L, Lovato B, Laharie D, Bertet J, Couzigou P \& de Ledinghen $\mathrm{V}$. Is liver stiffness mesurement useful in genetic hemochromatosis and hepatosiderosis? J Hepatol. 2006; 44: S242

Aguirre DA, Behling CA, Alpert E, Hassanein TI \& Sirlin CB. Liver fibrosis: noninvasive diagnosis with double contrast material-enhanced MR imaging. Radiology 2006;239:425-437

Aube C, Racineux PX, Lebigot J, Oberti F, Croquet V, Argaud C, Cales P, Caron C. Diagnosis and quantification of hepatic fibrosis with diffusion weighted MR imaging: preliminary results. J Radiol 2004;85:301-306

Berzigotti A, Nicolau C, Bellot P, Abraldes JG, Gilabert R, García-Pagan JC \& Bosch J. Evaluation of Regional Hepatic Perfusion (RHP) by Contrast-ENHANCED Ultrasound in Patients with Cirrhosis. J Hepatol. 2010 Dec 14. [Epub ahead of print]

Boeker KH, Haberkorn CI, Michels D, Flemming P, Manns MP \& Lichtinghagen R. Diagnostic potential of circulating TIMP-1 and MMP-2 as markers of liver fibrosis in patients with chronic hepatitis C. Clin Chim Acta. 2002;316:71-81

Bourliere M, Penaranda G, Renou C, Botta-Fridlund D, Tran A, Portal I, Lecomte L, Castellani P, Rosenthal-Allieri MA, Gerolami R, Ouzan D, Deydier R, Degott C \& Halfon P. Validation and comparison of indexes for fibrosis and cirrhosis prediction in chronic hepatitis $C$ patients: proposal for a pragmatic approach classification without liver biopsies. J Viral Hepat. 2006;13:659-70 
Castera L, Vergniol J, Foucher J, Le Bail B, Chanteloup E, Haaser M, Darriet M, Couzigou P \& De Ledinghen V. Prospective comparison of transient elastography, Fibrotest, APRI, and liver biopsy for the assessment of fibrosis in chronic hepatitis C. Gastroenterology 2005; 128: 343-350

Cholongitas E, Senzolo M, Standish RA, Marelli L, Quaglia A, Patch D, Dhillon AP \& Burroughs AK. A systemic review of the quality of liver biopsy specimens. Am J Clin Pathol 2006; 125: 710-21

Colletta C, Smirne C, Fabris C, Toniutto P, Rapetti R, Minisini R \& Pirisi M. Value of two noninvasive methods to detect progression of fibrosis among HCV carriers with normal aminotransferases. Hepatology. 2005;42:838-45

Croquet V, Vuillemin E, Ternisien C, Pilette C, Oberti F, Gallois Y, Trossaert M, Rousselet MC, Chappard D \& Calès P. Prothrombin index is an indirect marker of severe liver fibrosis. Eur J Hepatol 2002;14:1133-41

Davidson LE, Kuk JL, Church TS \& Ross R. Protocol for measurement of liver fat by computed tomography. J Appl Physiol. 2006;100:864-8

Dugoni M, Miglioli L, Borelli L, Anderlini R, Bedogni G, Mariano M, Battistini N, \& Bellentani S. Doppler perfusion index (DPI) and homa are highly predictive of fatty liver in patients with NAFLD. Dig Liver Dis 2007;40:A39.

Forns X, Ampurdanès S, Llovet JM, Aponte J, Quintó L, Martínez-Bauer E, Bruguera M, Sánchez-Tapias JM \& Rodés J. Identification of chronic hepatitis C patients without hepatic fibrosis by a simple predictive model. Hepatology. 2002;36:986-92

Friedrich-Rust M, Müller C, Winckler A, Kriener S, Herrmann E, Holtmeier J, Poynard T, Vogl TJ, Zeuzem S, Hammerstingl R \& Sarrazin C. Assessment of liver fibrosis and steatosis in PBC with FibroScan, MRI, MR-spectroscopy, and serum markers. J Clin Gastroenterol. 2010;44:58-65

Gandhi SN, Brown MA, Wong JG, Aguirre DA \& Sirilin CB. MR contrast agents for liver imaging: what, when, how. Radiographics 2006;26:1621-1636

Girometti R, Furlan A, Bazzocchi M, Soldano F, Isola M, Toniutto P, Bitetto D \& Zuiani C. Diffusion-weighted MRI in evaluating liver fibrosis: a feasibility study in cirrhotic patients. Radiol Med 2007;112:394-408

Hardwick RN, Fisher CD, Canet MJ, Lake AD \& Cherrington NJ. Diversity in antioxidant response enzymes in progressive stages of human nonalcoholic fatty liver disease. Drug Metab Dispos 2010;38:2293-301

Hussain SM \& Semelka RC. Hepatic imaging: comparison of modalities. Radiol Clin North Am 2005;43:929-947

Klatt D, Asbach P, Rump J, Papazoglou S, Somasundaram R, Modrow J, Braun J \& Sack I. In vivo determination of hepatic stiffness using steady-state free precision magnetic resonance elastography. Invest Radiol 2006;41:841-848

Kleiner DE, Brunt EM, Van Natta M, Behling C, Contos MJ, Cummings OW, Ferrell LD, Liu YC, Torbenson MS, Unalp-Arida A, Yeh M, McCullough AJ \& Sanyal AJ; Nonalcoholic Steatohepatitis Clinical Research Network. Design and validation of a histological scoring system for nonalcoholic fatty liver disease. Hepatol. 2005 ; 41:1313-1321

Koda M, Matunaga Y, Kawakami M, Kishimoto Y, Suou T \& Murawaki Y. Fibroindex, a practical index for predicting significant fibrosis in patients with chronic hepatitis C. Hepatology 2007;45:297-306 
Koinuma M, Ohashi I, Hanafusa K \& Shibuya H. Apparent diffusion coefficient measurements with diffusion-weighted magnetic resonance imaging for evaluation of hepatic fibrosis. J Magn Reson Imaging 2005;22:80-85

Kruse SA, Smith JA, Lawrence AJ, Dresner MA, Manduca A, Greenleaf JF \& Ehman RL. Tissue characterization using magnetic resonance elastography: preliminary results. Phys Med Biol 2000;45:1579-1590

Kyriakopoulou K, Antoniou A, Fezoulidis IV, Kelekis NL, Dalekos GN \& Vlychou M. The role of Doppler Perfusion Index as screening test in the characterization of focal liver lesions. Dig Liver Dis. 2008;40:755-60.

Leroy V, Monier F, Bottari S, Trocme C, Sturm N, Hilleret MN, Morel F \& Zarski JP. Circulating matrix metalloproteinases 1, 2, 9 and their inhibitors TIMP-1 and TIMP2 as serum markers of liver fibrosis in patients with chronic hepatitis C: comparison with PIIINP and hyaluronic acid. Am J Gastroenterol. 2004;99:271-9

Marek B, Mazurek U, Janczewska-Kazek E, Strzałka B, Beniowski M, Kos-Kudła B, Kajdaniuk J, Niedziołka D, Ostrowska Z, Borgiel-Marek H, Siemińiska L, Nowak M, Pakuła D, Gatnar A, Gnot R \& Filipczyk P. Serum aminoterminal peptide of type III procollagen (PIIINP) and transforming growth factor-beta1 (TGF-beta1) levels in patients with chronic hepatitis B and C. Pol Arch Med Wewn. 2003 ;109:603-8

McHutchinson JG, Blatt LM, de Medina M, Craig JR, Conrad A, Shiff ER \& Tong MJ. Measurement of serum hyaluronic acid levels in patients with chronic hepatitis $\mathrm{C}$ and its relationship to the liver histology. Consensus Interferon Study Group. J Gastroenterol Hepatol 2000;15:945-51

Myers RP, Benhamou Y, Imbert-Bismut F, Thibault V, Bochet M, Charlotte F, Ratziu V, Bricaire F, Katlama C \& Poynard T. Serum biochemical markers accurately predict liver fibrosis in HIV and hepatitis $C$ virus-coinfected patients. AIDS 2003; 17: 721-25

Myers RP, Tainturier MH, Ratziu V, Piton A, Thibault V, Imbert-Bismut F, Messous D, Charlotte F, Di Martino V, Benhamou Y \& Poynard T. Prediction of liver histological lesions with biochemical markers in patients with chronic hepatitis B. J Hepatol. 2003;39:222-30.

Naganawa S, Kawai H, Fukatsu H, Sakurai Y, Aoki I, Miura S, Mimura T, Kanazawa H \& Ishigaki T. Diffusion-weighted imaging of the liver: technical challenges and prospects for the future. Magn Reson Med Sci 2005;4:175-186

Naveau S, Raynard B, Ratziu V, Abella A, Imbert-Bismut F, Messous D, Beuzen F, Capron F, Thabut D, Munteanu M, Chaput JC \& Poynard T. Biomarkers for the prediction of liver fibrosis in patients with chronic alcoholic liver disease (ALD). Clin Gastroenterol Hepatol. 2005; 3: 167-74

Neuman G, Sagi R, Shalitin S \& Reif S. Serum inflammatory markers in overweight children and adolescents with non-alcoholic fatty liver disease. IMAJ 2010; 12: 410-415

Numminen K, Tervahartiala P, Halavaara J, Isoniemi H \& Hockerstedt K. Non-invasive diagnosis of liver cirrhosis: magnetic resonance imaging presents special features. Scand J Gastroenterol 2005;40:76-82

O'Regan DP, Callaghan MF, Wylezinska-Arridge M, Fitzpatrick J, Naoumova RP, Hajnal JV \& Schmitz SA. Liver fat content and T2*: simultaneous measurement by using breathhold multiecho MR imaging at 3.0 T--feasibility. Radiology 2008; 247: 550-557

Palekar NA, Naus R, Larson SP, Ward J \& Harrison SA. Clinical model for distinguishing nonalcoholic steatohepatitis from simple steatosis in patients with nonalcoholic fatty liver disease. Liver Int. 2006;26:151-6 
Park SH, Kim PN, Kim KW, Lee SW, Yoon SE, Park SW, Ha HK, Lee MG, Hwang S, Lee SG, Yu ES \& Cho EY. Macrovesicular hepatic steatosis in living liver donors: use of CT for quantitative and qualitative assessment. Radiology 2006; 239: 105-112

Patel K, Lajoie A, Heaton S, Pianko S, Behling CA, Bylund D, Pockros PJ, Blatt LM, Conrad A \& McHutchison JG. Clinical use of hyaluronic acid as a predictor of fibrosis change in hepatitis C. J Gastroenterol Hepatol. 2003;18:253-7

Patel K, Gordon SC, Jacobson I, Hézode C, Oh E, Smith KM, Pawlotsky JM \& McHutchison JG. Evaluation of a panel of non-invasive serum markers to differentiate mild from moderate-to-advanced liver fibrosis in chronic hepatitis C patients. J Hepatol. 2004 ;41:935-42

Poynard T, Imbert-Bismut F, Ratziu V, Chevret S, Jardel C, Moussalli J, Messous D \& Degos F; GERMED cyt04 group. Biochemical markers of liver fibrosis in patients infected by hepatitis $C$ virus: longitudinal validation in a randomized trial. J Viral Hepatitis. 2002; 9:128-33

Poynard T, McHutchison J, Manns M, Myers RP \& Albrecht J. Biochemical surrogate markers of liver fibrosis and activity in a randomized trial of peginterferon alfa- $2 b$ and ribavirin. Hepatology. 2003; 38: 481-92

Poynard T, Imbert-Bismut F, Munteanu M, Messous D, Myers RP, Thabut D, Ratziu V, Mercadier A, Benhamou Y \& Hainque B. Overview of the diagnostic value of biochemical markers of liver fibrosis (FibroTest, HCV FibroSure) and necrosis (ActiTest) in patients with chronic hepatitis C. Comp Hepatol. 2004; 3:8-19

Poynard T, Ratziu V, Naveau S, Thabut D, Charlotte F, Messous D, Capron D, Abella A, Massard J, Ngo Y, Munteanu M, Mercadier A, Manns M \& Albrecht J. The diagnostic value of biomarkers (SteatoTest) for the prediction of liver steatosis. Comp Hepatol. 2005 Dec 23;4:10

Ratziu V, Massard J, Charlotte F, Messous D, Imbert-Bismut F, Bonyhay L, Tahiri M, Munteanu M, Thabut D, Cadranel JF, Le Bail B, De Ledinghen V \& Poynard T, the LIDO Study Group and the CYTOL Study Group Diagnostic value of biochemical markers (FibroTest-FibroSURE) for the prediction of liver fibrosis in patients with non-alcoholic fatty liver disease. BMC Gastroenterology 2006, 6:6

Resino S, Bellón JM, Asensio C, Micheloud D, Miralles P, Vargas A, Catalán P, López JC, Alvarez E, Cosin J, Lorente R, Muñoz-Fernández MA \& Berenguer J. Can serum hyaluronic acid replace simple non-invasive indexes to predict liver fibrosis in HIV/Hepatitis C coinfected patients?. BMC Infectious Diseases 2010 10:244

Sandrin L, Fourquet B, Hasquenoph JM, Yon S, Fournier C, Mal F, Christidis C, Ziol M, Poulet B, Kazemi F, Beaugrand M \& Palau R. Transient elastography: a new noninvasive method for assessment of hepatic fibrosis. Ultrasound Med Biol. 2003;29:1705-13

Schiavon LL, Schiavon JL, Filho RJ, Sampaio JP, Lanzoni VP, Silva AE \& Ferraz ML. Simple blood tests as noninvasive markers of liver fibrosis in hemodialysis patients with chronic hepatitis C virus infection. Hepatology. 2007;46:307-14

Semelka RC, Chung JJ, Hussain SM, Marcos HB \& Woosley JT. Chronic hepatitis: correlation of early patchy and late linear enhancement patterns on gadolinium-enhanced MR images with histopathology initial experience. J Magn Reson Imaging 2001;13:385391

Shaheen AA \&, Myers RP. Diagnostic accuracy of the aspartate aminotransferase to-platelet ratio index for the prediction of hepatitis C-related fibrosis: a systematic review. Hepatology 2007; 46:912-920 
Shimada M, Kawahara H, Ozaki K, Fukura M, Yano H, Tsuchishima M, Tsutsumi M \& Takase S. Usefulness of a combined evaluation of the serum adiponectin level, HOMA-IR, and serum type IV collagen $7 \mathrm{~S}$ level to predict the early stage of nonalcoholic steatohepatitis. Am J Gastroenterol. 2007 ;102:1931-8

Solga SF, Horska A, Clark JM \& Diehl AM. Hepatic 31P magnetic resonancespectroscopy: a hepatologist's user guide. Liver Int 2005;25:490-500

Szczepaniak LS, Nurenberg P, Leonard D, Browning JD, Reingold JS, Grundy S, Hobbs HH \& Dobbins RL. Magnetic resonance spectroscopy to measure hepatic triglyceride content: prevalence of hepatic steatosis in the general population. Am J Physiol Endocrinol Metab 2005; 288: E462-E468

Talwalkar JA, Yin M, Fidler JL, Sanderson SO, Kamath PS \& Ehman RL. Magnetic resonance imaging of hepatic fibrosis: emerging clinical applications. Hepatology. 2008; 47:332-42

Trabut JB, Mallet V \& Pol S. Aspartate aminotransferase to platelet ratio index (APRI) score is inappropriate for assessment of liver fibrosis in HIV-infected patients with hazardous drinking. HIV Med. 2009;10:524

Vallet-Pichard A, Mallet V, Nalpas B, Verkarre V, Nalpas A, Dhalluin-Venier V, Fontaine H \& Pol S. FIB-4: an inexpensive and accurate marker of fibrosis in HCV infection. comparison with liver biopsy and Fibrotest. Hepatology 2007;46:32-6

Wai CT, Greenson JK, Fontana RJ, Kalbfleisch JD, Marrero JA, Conjeevaram HS \& Lok AS. A simple noninvasive index can predict both significant fibrosis and cirrhosis in patients with chronic hepatitis C. Hepatology. 2003;38:518-26

Walsh KM, Fletcher A, MacSween RN \& Morris AJ. Basement membrane peptides as markers of liver disease in chronic hepatitis C.J Hepatol. $2000 ; 32: 325-30$

Webb M, Hanny Yeshua H, Zelber-Sagie S, Santo M, Barazovski E, Katz R, Halpern Z \& Oren R. Diagnostic value of a computerized hepatorenal index for sonographic quantification of liver steatosis. AJR Am J Roentgenol 2009 ;192:909-14

Wieckowska A, McCullough AJ \& Feldstein AE. Noninvasive diagnosis and monitoring of nonalcoholic steatohepatitis: present and future. Hepatology 2007; 46: 582-589

Wieckowska A, Papouchado BG, Li Z, Lopez R, Zein NN \& Feldstein AE. Increased hepatic and circulating interleukin-6 levels in human nonalcoholic steatohepatitis. Am J Gastroenterol 2008; 103: 1372-1379

Yamashita Y, Yamamoto H, Hirai A, Yoshimatsu S, Baba Y \& Takahashi M. MR imaging enhancement with superparamagnetic iron oxide in chronic liver disease: influence of liver dysfunction and parenchymal pathology. Abdom Imaging 1996;21:318-323

Yin M, Talwalkar JA, Glaser KJ, Manduca A, Grimm RC, Rossman PJ, Fidler JL \&, Ehman RL. Assessment of hepatic fibrosis with magnetic resonance elastography. Clin Gastro Hep 2007;5:1207-1213

Yoneda M, Mawatari H, Fujita K, Iida H, Yonemitsu K, Kato S, Takahashi H, Kirikoshi H, Inamori M, Nozaki Y, Abe Y, Kubota K, Saito S, Iwasaki T, Terauchi Y, Togo S, Maeyama $S$ \& Nakajima A. High-sensitivity C-reactive protein is an independent clinical feature of nonalcoholic steatohepatitis (NASH) and also of the severity of fibrosis in NASH. J Gastroenterol 2007; 42: 573-582

Yoneda M, Uchiyama T, Kato S, Endo H, Fujita K, Yoneda K, Mawatari H, Iida H, Takahashi H, Kirikoshi H, Inamori M, Nozaki Y, Kobayashi N, Kubota K, Saito S, Maeyama S, Sagara M, Aburatani H, Kodama T \& Nakajima A. Plasma Pentraxin-3 is a novel marker for nonalcoholic steatohepatitis (NASH). BMC Gastroenterol 2008; 8: 53

Zaman A, Rosen HR, Ingram H, Corless CL, Oh E \& Smith K. Assessement of Fibrospect II to detect hepatic fibrosis in chronic hepatitis C patients Am J Med 2007;120:280 


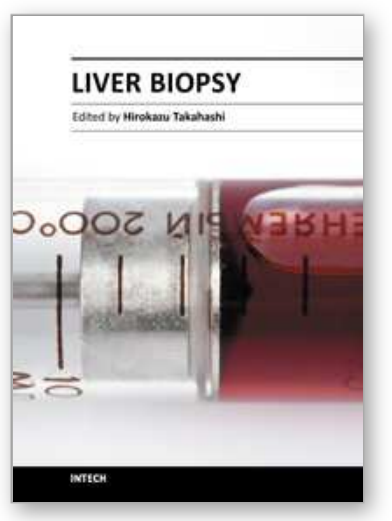

\author{
Liver Biopsy \\ Edited by Dr Hirokazu Takahashi
}

ISBN 978-953-307-644-7

Hard cover, 404 pages

Publisher InTech

Published online 06, September, 2011

Published in print edition September, 2011

Liver biopsy is recommended as the gold standard method to determine diagnosis, fibrosis staging, prognosis and therapeutic indications in patients with chronic liver disease. However, liver biopsy is an invasive procedure with a risk of complications which can be serious. This book provides the management of the complications in liver biopsy. Additionally, this book provides also the references for the new technology of liver biopsy including the non-invasive elastography, imaging methods and blood panels which could be the alternatives to liver biopsy. The non-invasive methods, especially the elastography, which is the new procedure in hot topics, which were frequently reported in these years. In this book, the professionals of elastography show the mechanism, availability and how to use this technology in a clinical field of elastography. The comprehension of elastography could be a great help for better dealing and for understanding of liver biopsy.

\title{
How to reference
}

In order to correctly reference this scholarly work, feel free to copy and paste the following:

Anna Mania, Paweł Kemnitz, Katarzyna Mazur-Melewska, Magdalena Figlerowicz and Wojciech Służewski (2011). Non-Invasive Assessment of the Liver - Serum Markers and Imaging Techniques, Liver Biopsy, Dr Hirokazu Takahashi (Ed.), ISBN: 978-953-307-644-7, InTech, Available from:

http://www.intechopen.com/books/liver-biopsy/non-invasive-assessment-of-the-liver-serum-markers-andimaging-techniques

\section{INTECH}

open science | open minds

\section{InTech Europe}

University Campus STeP Ri

Slavka Krautzeka 83/A

51000 Rijeka, Croatia

Phone: +385 (51) 770447

Fax: +385 (51) 686166

www.intechopen.com

\section{InTech China}

Unit 405, Office Block, Hotel Equatorial Shanghai

No.65, Yan An Road (West), Shanghai, 200040, China

中国上海市延安西路65号上海国际贵都大饭店办公楼 405 单元

Phone: +86-21-62489820

Fax: $+86-21-62489821$ 
(C) 2011 The Author(s). Licensee IntechOpen. This chapter is distributed under the terms of the Creative Commons Attribution-NonCommercialShareAlike-3.0 License, which permits use, distribution and reproduction for non-commercial purposes, provided the original is properly cited and derivative works building on this content are distributed under the same license. 